\title{
Study Into Gamification and Awareness of Sustainability Amongst Young Adults
}

\author{
Lucie Magnusson \\ Edinburgh Napier University \\ 219 Colinton Rd, Edinburgh, United Kingdom \\ lucmagnuss@gmail.com
}

\author{
Dr Emilia Sobolewska \\ Edinburgh Napier University \\ 219 Colinton Rd, Edinburgh, United Kingdom \\ e.sobolewska@napier.ac.uk
}

\begin{abstract}
The importance of sustainability is evident and each of us is encouraged to take part in sustainable behaviour in some way. However, do we know what sustainability really means and are young adults prepared to be sustainable to protect the Earth for another generation? The aim of this pilot study was to investigate, whether implementation of gamification principles in a mobile application called Urban Eco can raise awareness of sustainability amongst young adults aged between 16-30. This pilot study was conducted through unstructured interviews, questionnaires and observation to investigate the phenomena from the young adults' point of view. Relevant data was analysed using Interpretative Phenomenological Analysis, and it revealed that participants were deeply lacking in relevant knowledge of sustainability. This illustrates that despite ongoing efforts, there is still space to improve young adult's familiarity and understanding of sustainable behaviours. The initial findings were then used to inform the development of two prototype versions of The Urban Eco App. The two apps, Version A, lacking gamification, and Version B, including gamification were subsequently tested using AttrakDiff, followed up by open-end questionnaires. This study revealed, that while participants found the functionality of the applications similar, the application lacking gamification was rated as more pleasing. The follow up interviews did not reject or approve the hypothesis, that implementation of gamification can improve awareness of sustainability amongst young adults as participants shown similar improvements in both cases.
\end{abstract}

\section{Sustainability, Gamification, Mobile Applications}

\section{INTRODUCTION}

The need for sustainable behaviour has grown in importance, as depletion and overuse of natural resources continues to have a negative impact on the ecosystem and humans (Haran, et al., 2013). Every day, about 677,000 children and young adults in Scotland are encouraged to embrace sustainable behaviour in their school curriculums (Education.gov, 2015). While this encourages an increase in sustainable behaviour amongst the younger population, there is still more work to be done. This pilot study investigated whether applying gamification principles in a mobile application to encourage sustainable behaviour, with a focus on recycling, would raise awareness about sustainability amongst young adults.

\section{SUSTAINABILITY}

"Our Common Future" initially defined sustainability as a search for a sustainable path (WCED, 1987). Since then, sustainability has been investigated further and divided into three groups, namely: social, economic and environmental (United Nations General Assembly, 2005). Social sustainability may be described as a positive process within communities, working towards a common goal (McKenzie, 2004). Sustainable development goals outline a total of seventeen areas covering social developmental issues. These include: poverty; hunger; health well-being; education; gender equality; clean water and sanitation; affordable and clean energy; work and economic growth; industry, innovation and infrastructure; reduced inequalities; sustainable cities and communities; responsible consumption and production; climate change; life below water; and on land; peace, justice and strong institutions and partnerships for the goals (UN.org., 2017). Economic sustainability is defined as a requirement to maintain a permanent income for humankind (Spangenberg, 2005). This requires a set of actions to be performed by humans now, which will not reduce the prospect of humans in the future, who should enjoy the same levels of consumption, wealth, utility and welfare (Bromley, 2008). Environmental sustainability is portrayed as maintenance of natural capital (Goodland, 1995), explained as resources from Earth that supports life, for example: minerals, water or oxygen (Srinivas, 2017). Kuhlman and Farrington (2010) identified that while environmental concerns are significant, the importance of welfare in the context of intergenerational equity is crucial. People should care for environment in order to preserve resources for their descendants rather than for its inherent value.

Neumayer, (2003), proposes finding a middle ground, and further categorizes sustainability into weak and strong. Weak sustainability infers that human capital can replace natural capital. This concept refers to human beings as the means and contributing factors in economic growth and social 
development with the use of knowledge, experience, intellectual property and labour (Šlaus \& Jacobs, 2011). Strong sustainability assumes that human and natural capital are complementary - not replacing each other (Neumayer, 2003). Furthermore, Kuhlman and Farrington (2010) suggest that weak and strong sustainability do not need to be opposites, but rather complement one another.

\subsection{Sustainability in $\mathrm{HCl}$}

Research has shown that there are some foundations missing that would link contemporary Human-Computer Interaction $(\mathrm{HCl})$ and Sustainability (Dourish, 2010). Benyon et al. (2016) recognised that interaction designers should account not only for space and movement, but also for interaction with technology. DiSalvo et al. (2010) proposed that there is a lack of debate between different approaches to Sustainable $\mathrm{HCl}$. Hauser et al. (2013) published research regarding sustainable future, suggesting that researchers and designers must re-consider values, directions and positions towards Sustainable $\mathrm{HCl}$.

It appears that $\mathrm{HCl}$ needs to start creating effective solutions embracing sustainability. This paper proposes the use of gamification principles as a tool to raise awareness about sustainability amongst young adults.

\section{GAMIFICATION}

The term "Gamification" often features in Interaction Design or Playful Interaction as a "synonym" for enhancing user interaction, engagement and productivity (Deterding, et al., 2011). The authors defined gamification as use of game design elements in non-game contexts; they also offer an alternative term of "gameful design". Gamification techniques are used in a wide range of industries from education (Code Academy, 2017), healthcare (Fitbit.com, 2017) to army recruitment (Army.mil, 2017), and may be a rewarding tool for the participants if applied appropriately. There are already some studies concerned with applying gamification principles to sustainability orientated applications. Gustafsson, et al., (2009), describe a pervasive game created to encourage teenagers and their families to reduce energy consumption in their home, through learning and competition. The authors present a mobile-based application rewarding each team points, when the energy is saved. The outcomes demonstrated that the introduction of gamification was successful, especially when it involved personalizing data and the use of motivation. Motivation was powered by the competitive aspect of the game and peer pressure to achieve the best possible results. Although the long-term behavioural changes were not documented, it was shown that it is possible to encourage users to change or alternate their habits if rewarded with achievements. Another example was a pilot study involving 26 participants, interacting with a mobile application called Orientation passport (Fitz-Walter et al., 2011). The authors explored the use of game achievements to assist new students on their personalized orientation day at the University. This involved meeting new friends and finding out about services and events on campus. The study explored the relationship between usability and engagement. It showed that applying game elements is often successful, however, it depends upon input type. Achievements that depended on numerical input were found to be less enjoyable as they could be achieved by trial and error. Instead, interactive content, such as finding a location or check-in improves enjoyment and the challenge. While the results were primarily positive, the study also uncovered potential issues. Although the achievements encouraged the user to engage more, it also highlighted that applying game elements affects the functionality of the mobile application. The Urban Eco application applied principles derived from these two studies. The challenges and points to motivate users through competitive aspect of a game to reach the best result, while implementing badges would give the user a feeling of satisfaction and achievement.

\section{STUDIES OF SUSTAINABLE BEHAVIOUR}

A qualitative study was conducted involving measures to capture a deep understanding of the young adults' views and actions towards the phenomenon of sustainability. To explore the views of young adults, interviews, questionnaires and observations were carried out.

Table 1: Data collection schedule

\begin{tabular}{|l|l|l|}
\hline \multicolumn{3}{|c|}{ Data collection schedule } \\
\hline Interviews & Questionnaires & Observations \\
\hline 3 participants & 7 participants & 35 participants \\
\hline Up to 15 min & Up to 10 min & Up to 1 hour \\
\hline
\end{tabular}

\subsection{Initial research}

Initial research examined the phenomena through unstructured interviews. The selected topics included:

- General knowledge about sustainability

- Motivation for sustainable behaviour

- Mobile applications for sustainable behaviour

- Gamification

The study involved an opportunistic sample of three participants aged between 16 and 30 , competent and efficient in use of smartphones, who had a general idea about topics of sustainability and gamifications. The procedure included recording and 
transcription of the obtained data. The interviews lasted about 15 minutes each, depending on the participant's knowledge.

Subsequently, analysis of interviews revealed the need for deploying questionnaires. The participants group reflected the demographics of previously engaged interviewees.

There were 10 questionnaires deployed, 7 were returned. Questions included topics such as:

- Perception of sustainability

- Knowledge of sustainability

- Motivation towards sustainability

The procedure included sending links to prospective participants with clear instructions of how to fill in the form. Google Forms was used to create and deploy the questionnaires.

Lastly, an in-situ overt observation explored the use of recycling bins by University library goers, in order to establish:

- How often is the recycling bin used?

- Are the items disposed in correct bins?

- Do the locations of the bins affect the recycling behaviour?

During first thirty minutes of observation, the recycling and general bins were in the same location. For the other half of the observation, the recycling bins were relocated further back leaving the general bin closer to the participants.

To examine the data obtained, the Interpretative Phenomenological Analysis (Smith, et al. 2009) was applied which followed these steps: immersion in data; noting initial content and language; development of emerging themes; search for associations, and finally search for patterns across the interviews, questionnaires and observations.

\subsubsection{Initial findings}

The interviews revealed that participants were lacking in relevant knowledge to provide informative answers. This illustrates that despite ongoing efforts, there is still space to improve their familiarity and understanding of sustainable behaviours.

The questionnaires revealed some knowledge about sustainability, and that $71.4 \%$ of participants recycle. However, this appeared superficial, as behavioural cues were missing. When asked, participants were unable to identify simple locations, for instance, the nearest recycling point. From a technology point of view, the questionnaires also revealed that $42.9 \%$ of participants did not play mobile games.

The observations supported the findings that some young adults do recycle. The participants easily recognised most recyclable items, however, plastic wrapping and takeaway drink cups were creating confusion. The interesting finding and a key factor appeared to be convenience. Although the recycling bins were only a few steps further than the general bin, when facing a choice of near versus far, young adults would often throw recycling items in the general bin as it was closer.

The analysis of the obtained data subsequently led to designing an Urban Eco - sustainability-based app concept. To create an understanding of sustainable behaviour of Urban Eco users, three personas were created:

(i) Person who has no knowledge of recycling,

(ii) Person who has superficial knowledge, not followed up with relevant behaviour,

(iii) Person who chooses convenience over sustainable behaviour

\subsection{Evaluation of the Prototypes}

To explore the visual design of Urban Eco, two wireframes were created. Version A and Version B had the same content and modes of interaction, however, they were differentiated by the use $[A]$, or lack of gamification principles [B]. These principles included: badges, points and challenges. The wireframes solely focused on recycling as an indicator to sustainable behaviour.

The wireframes were tested by three participants. Each participant previewed both applications and their opinions were recorded through questionnaire using open-ended questions. The participants were recruited through opportunistic sampling and aged between 16 and 30 years old. All participants had previous experience with mobile applications.

The testing of the two wireframes revealed that Urban Eco needed to include a social element. The participants felt that it would have an "encouraging aspect" (P1), "to see other people's actions/profiles would maybe make me want to use this app" (P1) and "it would be good to share on social media" (P3).

Subsequently, low-fidelity paper prototypes of Urban Eco Version A and Version B were created. The prototypes simulated the use of the application according to recommended changes. Both lowfidelity prototypes were previewed by the participants, subsequently, responses were recorded through open questions in a questionnaire.

The participants performed in a controlled environment, and were asked to complete three tasks:

- Log in into the application

- Preview their profile

- Recycle 2 glass bottles

The participants found the applications both interesting and provided just enough information to learn more about recycling. Some participants were concerned about the possibility of cheating. Once 
the user recycled 2 glass bottles, the next step was to reward themselves by clicking the "Reward yourself" button to obtain points, whilst Version A did not include this option.

Consequently, the high-fidelity prototypes, were created with the use of InVision (InVision, 2018). These were designed to simulate the interactions of a functional mobile application and were subsequently tested on an Android mobile phone. These prototypes were deployed, to investigate relevance of engagement and pleasure in order to establish whether implementation of gamification has increased awareness of sustainability amongst young adults.

To test the high-fidelity prototypes, 10 participants were recruited, aged between 16 and 30 years old. All participants had previous experience with the use of mobile applications as they all owned Android smartphones. Each version was tested by 5 participants, who were given 4 tasks:

- Log in into the application

- Preview latest notifications

- Recycle 2 cans

- Recycle 4 batteries

AttrakDiff (Attrakdiff.de, 2018) was deployed to measure usability and design qualities, including:

- Pragmatic quality (PQ) concerned with the usability of the product

- Hedonic quality (HQ-S) showcasing the stimulation provided by the Urban Eco

- Hedonic quality (HQ-I) expressing the way user can identify with the product

- Attractiveness (ATT) describing the value of the Urban Eco based on quality perception

Afterwards, final questionnaires were deployed to establish whether implementation of gamification can raise awareness on sustainability amongst young adults.

\subsection{Results}

The portfolio-presentation (Figure 1) demonstrates average values of Pragmatic and Hedonic Quality. The Pragmatic qualities of Version A and Version $B$ are comparatively similar with $P Q=1.71$ and $P Q=$ 1.29. This means that the functionality of these applications appeared similar to the participants. However, regarding the Hedonic Quality - Version A was held higher than Version $B$, showing that participants felt that the application without gamification is more pleasing.

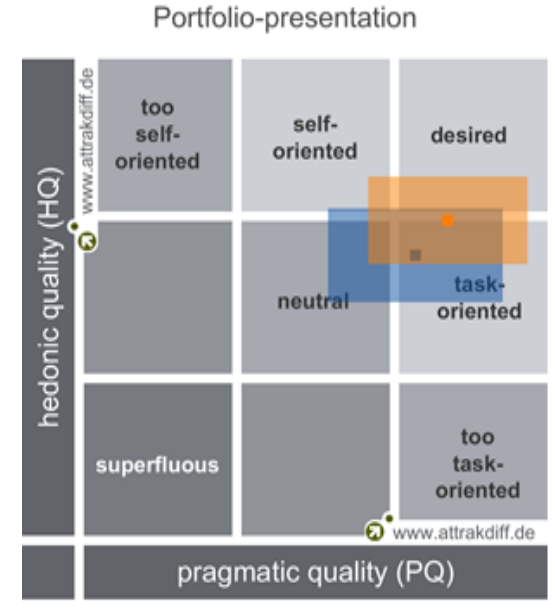

- Product:Urban Eco ( $\mathrm{n}=5)$ PQ:1,29 Confidence: 1,12 HQ: 0,53 Confidence: 0,59

- Product:Urban Eco (n=5) PQ:1,71 Confidence: 1,03 HQ:0,99 Confidence: 0,55

Figure 1: Portfolio with average values of dimensions $P Q$ and $H Q$ and the confidence rectangle of Urban Eco App A (Orange) and App B (Blue).

The follow up, open-ended question responses did not support or disprove the hypothesis that implementation of gamification can improve awareness of sustainability amongst young adults as participants showed similar improvements in both cases. Thus, further study is required.

\section{DISCUSSION AND CONCLUSIONS}

The aim of this study was to investigate, whether implementation of gamification in mobile applications can raise awareness about sustainability amongst young adults. The investigation included initial research of the phenomena, which led to the creation of wireframes, low, and high-fidelity prototypes, which were subsequently tested using AttrakDiff tool, and a questionnaire including open ended questions.

The results have shown that while both applications are functional on a similar level, the application without gamification was more pleasant to the participant. This initial study examined the potential impact of gamification on influencing sustainable behaviour and methods measuring satisfaction with different approaches. The research was limited by the depth of the challenges for the participants and the sample size. Further work could increase challenge and motivation in a working prototype by creating the game elements more meaningful to the participants, possibly including reward system.

Further study is required to determine, if implementation of gamification can raise awareness of sustainability as the open-ended questionnaires for application $A$ and $B$ revealed, that there was an increase of awareness in both instances, making it difficult to determine, if this hypothesis can be accepted or rejected. Additionally, it is important to further investigate the role of social networking, as this appeared to be an important and expected part of the application. 


\section{REFERENCES}

Attrakdiff.de. (2018). AttrakDiff. [online] Available at: $\quad$ http://www.attrakdiff.de/index-en.html, [Accessed 28 Mar. 2018].

Benyon, D. \& Mival, O. (2016). Designing Blended Spaces for Collaboration. In Human Computer Confluence; Transforming Human Experience Through Symbiotic Technologies, 18-39. De Gruyter Open.

Bromley, D. W. (2008). The New Palgrave Dictionary of Economics, 2nd Edition.

Codecademy. (2017). Codecademy - learn to code, interactively, for free. Available at: https://www.codecademy.com/, [Accessed 28 Mar. 2018].

Deterding, S., Dixon, D., Khaled, R. and Nacke, L. (2011). From Game Design Elements to Gamefulness: Defining "Gamification”. Tampere: MindTrek'11

DiSalvo, C., Sengers, P. and Brynjarsdóttir, H. (2010). Mapping the landscape of sustainable $\mathrm{HCl}$. New York: $\mathrm{CHI}$ '10 Proceedings of the SIGCHI Conference on Human Factors in Computing Systems.

Dourish, P. (2010). HCl and Environmental Sustainability: The Politics of Design and the Design of Politics. Denmark: DIS 2010.

Fitbit.com. (2017). Fitbit Official Site for Activity Trackers and More. Available at: https://www.fitbit.com/uk/home, [Accessed 28 Mar. 2018].

Fitz-Walter, Z., Tjondronegoro, D. and Wyeth, P. (2011). Orientation Passport: Using gamification to engage university students. Canberra: $\mathrm{OZCHI}$.

Goodland, R. (1995). The Concept of Environmental Sustainability. 26th ed. Annual Reviews, pp. 1-24.

Gustafsson, A., Katzeff, C., and Bang, M. (2009). Evaluation of a pervasive game for domestic energy engagement among teenagers. Computers in Entertainment (CIE) - SPECIAL ISSUE: Games CIE Homepage archive, Vol. 7 Issue 4.

Haran, M., Nicholas, R. and Keller, K. (2013). The Role of Statistics in Sustainability Research. Network for Sustainable Climate Risk Management. Available at: http://www.eesi.psu.edu. [Accessed 28 Mar. 2018].

Hauser, S., Desjardins, A. and Wakkary, R. (2013). Rethinking and Envisioning Sustainable $\mathrm{HCl}$ and the Role of Interaction Design. Paris: $\mathrm{CHI} 13$.
InVision. (2018). Digital Product Design, Workflow \& Collaboration | InVision. [online] Available at: https://www.invisionapp.com/ [Accessed 27 Mar. 2018].

Kuhlman, T. and Farrington, J. (2010). What is Sustainability? Available at: http://www.mdpi.com [Accessed 28 Mar. 2018].

McKenzie, S. (2004). Social Sustainability. Towards some Definitions. 27th Edition Magill: Hawke Research Institute.

Neumayer, E. (2003). Weak versus strong sustainability: exploring the limits of two opposing paradigms. Northampton: Edward Elgar.

Opening Up Great Learning Learning for Sustainability (Education.gov) (2015). 2nd ed. Education Scotland, p.1.

Spangenberg, J. (2005). Economic sustainability of the economy: concepts and indicators. 8th Edition. Bad Oeynhausen: Int. J. Sustainable Development.

Srinivas, H. (2017). Sustainability Concepts: Natural Capital. Available at: https://www.gdrc.org. [Accessed 28 Mar. 2018].

Smith J., A., Flowers, P., and Larkin, M., (2009) Interpretative Phenomenological Analysis. Theory, Method and Research. SAGE, Los Angeles, London, New Delhi, Singapore, Washington DC.

Šlaus, I. and Jacobs, G. (2011). Human Capital and Sustainability. Sustainability, 3(12), pp.97154.

Un.org. (2017). United Nations Official Document. Available at: https://www.un.org/ga/search/view_doc.asp?sym bol=A/69/L.85\&Lang. [Accessed 28 Mar. 2018].

United Nations General Assembly (2005). 2005 World Summit Outcome, Resolution A/60/1, adopted by the General Assembly on 15 September 2005. Retrieved on: 2009-02-17.

World Commission on Environment and Development (WCED). (1987). Our Common Future, Oxford and New York: Oxford University Press.

www.army.mil. (2017). The Official Home Page of the United States Army. Available at: https://www.army.mil/. [Accessed 28 Mar. 2018]. 